\title{
Psychiatric morbidity, somatic comorbidity and substance use in an adolescent psychiatric population at 3-year follow-up
}

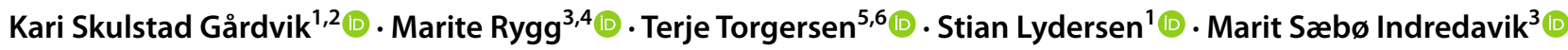

Received: 6 December 2019 / Accepted: 8 July 2020 / Published online: 15 July 2020

(c) The Author(s) 2020

\begin{abstract}
Knowledge is scarce on the course of psychiatric disorders in adolescence. We aimed to assess changes in the frequency of psychiatric disorders, somatic disorders, pain, and substance use in a clinical psychiatric cohort from adolescence to young adulthood. This study is part of the Health Survey in Department of Children and Youth, St. Olavs Hospital, Norway. At age 13-18 years, 717 (43.5\% of eligible) participated in the first study visit $\left(T_{1}\right)$ in 2009-2011, 549 were reassessed 3 years later with telephone interview $\left(T_{2}\right)$, and 464 had diagnostic evaluation at both time points. Data included: ICD-10 diagnoses $\left(T_{1}\right)$, DSM-IV diagnoses $\left(T_{2}\right)$, self-reported pain and substance use $\left(T_{1}\right.$ and $\left.T_{2}\right)$. The overall rate of psychiatric disorders decreased ( $T_{1}$ vs. $T_{2}: 94.8 \%$ vs. $\left.72.2 \%, p<0.001\right)$; while, an increased rate of anxiety disorders was marked among girls $(37.5 \%$ vs. $55.9 \%, p<0.001)$, with accompanying raised frequencies of psychiatric comorbidity $(14.1 \%$ vs. $42.6 \%, p<0.001)$, somatic comorbidity $(9.4 \%$ vs. $19.5 \%, p=0.001)$, chronic pain $(31.6 \%$ vs. $49.4 \%, p<0.001)$, smoking, alcohol use and trying illicit drugs. Chronic pain, smoking and trying illicit drugs were associated with persisting psychiatric disorders, with highest risk differences for girls $(\mathrm{RD}=25.4 \%, p=0.002, \mathrm{RD}=15.6 \%, p=0.008, \mathrm{RD}=18.0 \%, p=0.001$, respectively). Three out of four adolescents still had a psychiatric disorder after 3 years. Unlike boys, girls had an increasing rate of anxiety disorders and comorbidities. Chronic pain, smoking and trying illicit drugs were associated with persisting psychiatric disorders. Despite methodological limitations, these findings emphasize the importance of early targeted intervention for adolescents with psychiatric disorders.
\end{abstract}

Keywords Mental disorders · Adolescent $\cdot$ Pain $\cdot$ Comorbidity $\cdot$ Longitudinal study

\section{Introduction}

An increasing focus on mental disorders in children and adolescents has revealed large variations in prevalence between nations [1]. The worldwide prevalence of mental disor-

Electronic supplementary material The online version of this article (https://doi.org/10.1007/s00787-020-01602-8) contains supplementary material, which is available to authorized users.

Kari Skulstad Gårdvik

kari.s.gardvik@ntnu.no

1 Department of Mental Health, Faculty of Medicine and Health Sciences, Regional Centre for Child and Youth Mental Health and Child Welfare, Norwegian University of Science and Technology, Trondheim, Norway

2 Division of Mental Health Care, Department of Children and Youth, St. Olavs Hospital, Trondheim University Hospital, Trondheim, Norway

3 Department of Clinical and Molecular Medicine (IKOM), Faculty of Medicine and Health Sciences, Norwegian University of Science and Technology, Trondheim, Norway ders in this age group was $13.4 \%$ in 2015 [2], with anxiety

4 Department of Pediatrics, St. Olavs Hospital, Trondheim University Hospital, Trondheim, Norway

5 Division of Mental Health Care, Department of Østmarka, St. Olavs Hospital, Trondheim University Hospital, Trondheim, Norway

6 Department of Mental Health, Faculty of Medicine and Health Sciences, Norwegian University of Science and Technology, Trondheim, Norway 
disorders as the most frequent disorder (6.5\%). In Norway, the reported prevalence is lower; $8 \%$ met the criteria for a psychiatric disorder requiring treatment in 2009 [3, 4]. Still, $15-20 \%$ of children and adolescents aged 3-18 years had reduced function due to symptoms of mental disorders [3-5]. Diagnoses differ with age and gender. Before puberty, more boys than girls are diagnosed, and conduct disorder and attention deficit/hyperactivity disorder (ADHD) dominates; while after puberty, the diagnoses and gender predominance shift to anxiety, depression and eating disorders among girls [6, 7]. For both genders, emerging adulthood represents a particularly vulnerable time for the initiation of mental health problems, including substance use $[6,8]$, and adolescence is the time at which a high burden of disease emerges from mental disorders [9].

Comorbidity of psychiatric disorders is common in children and adolescents, and increases by age [10,11]. Presence of co-occurring disorders is more marked in girls than in boys [10]. Among adults with psychiatric disorders, almost half have more than one disorder, and comorbidity continues to be more frequent in females [12]. Comorbid psychiatric disorders are challenging to assess and treat, especially in combination with co-existing somatic symptoms or disease [13]. Earlier research have found strong evidence for a relation between somatic symptoms and psychiatric disorders [14] and that psychiatric disorders of all types are associated with an increased risk of onset of a broad range of somatic conditions [15]. A systematic review demonstrated a strong positive association between chronic somatic disorders in adolescence and anxiety and depressive disorders [16]. A recent population-based Swedish study reported a high risk for concurrent somatic disorders in children with psychiatric disorders, across all ages and across many types of conditions [17].

Pain symptoms in adolescence involves an increased risk for mental distress in young adulthood [18, 19], and strong associations are reported between chronic pain and especially anxiety and depression [20]. Therefore, pain seems to be a common symptom and part of the complexity in many psychiatric disorders, especially in anxiety and depressive disorders. In the current sample of interest, when patients with psychiatric disorders were young adolescents, higher rates of chronic pain were found compared to the general adolescent population [21, 22]. In adults with psychiatric disorders, it is well known that chronic somatic conditions are frequent [23]. Still, knowledge is scarce on the longitudinal effect of psychiatric-somatic comorbidity from adolescence to adult age in a clinical psychiatric sample.

Co-existing substance use is another factor contributing to the complexity of mental disorders. Adolescent psychiatric patients have increased risk of substance use [24]. Harmful alcohol consumption combined with depression and anxiety is commonly observed $[25,26]$. A recent population-based survey linked with data from National Patient Registry in Norway, found that all investigated psychiatric diagnoses, except autism, were associated with some measure of hazardous alcohol/drug use, with highest odds among adolescents with trauma-related disorders, depression and conduct disorders [27].

Although having a psychiatric disorder in adolescence is a potent risk factor for having a psychiatric disorder in adulthood $[28,29]$, the frequency of psychiatric disorders is intuitively expected to decline in a clinical follow-up, due to treatment, individual maturation and other factors. However, knowledge is limited on the developmental course of psychiatric morbidity in interplay with co-occurring disorders and substance use in a clinical adolescent cohort. Such knowledge is highly wanted in clinical practice, as a necessary basis for intervention and specific treatment.

The objective of the present study was to examine the prevalence and associations of disorders in a clinical psychiatric cohort over a 3-year period from adolescence to young adulthood. The primary aim was to investigate any changes in the frequency of psychiatric disorders, comorbidities with other psychiatric or somatic disorders, chronic pain, and substance use, overall, by diagnostic groups, and separately for girls and boys. The secondary aim was to study if somatic disorders, chronic pain and substance use were associated with persisting psychiatric disorders, overall, by diagnostic groups, and separately for girls and boys. We hypothesized that the frequency of psychiatric disorders, i.e., anxiety, mood, ADHD and other psychiatric disorders (grouped) declined over the 3 years, and that continuity of a psychiatric disorder was associated with concurrent comorbid disorders, chronic pain and substance use at baseline. We further hypothesized that there would be a different pattern of morbidity for girls and boys.

\section{Methods}

\section{Study design}

The Health Survey in Department of Children and Youth, Division of Mental Health Care, St. Olavs hospital, Trondheim University Hospital, Norway (St. Olav CAP Survey), is a prospective longitudinal cohort study of a defined clinical population assessed at two time points. At time point $1\left(T_{1}\right)$, data were collected at inclusion in a cross-sectional study of adolescent patients; at time point $2\left(T_{2}\right)$ data were collected at a 3 -year follow-up.

At $T_{1}$ (2009-2011), all patients aged 13-18 years who visited the Department of Children and Youth (hereafter: CAP clinic) at least once over a 2-year period received both oral and written invitations at their first attendance during the study period. The exclusion criteria were difficulties in 
answering the survey due to an unstable psychiatric state, low cognitive function, visual impairments, or insufficient language skills. Emergency patients were invited to take part once they entered a stable phase. The participants and their parents received standard application of services. They gave written informed consent to extract diagnostic data from clinical charts and respond to an electronic survey. At $T_{2}$ (2012-2014), age 16-21 years, data were collected from the $T_{1}$ enrolled sample and their parents, by an electronic survey and a diagnostic telephone interview performed by trained professionals.

Fig. 1 Flow-chart of the recruitment and attrition in the present study

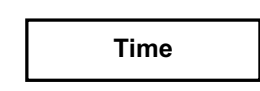

\section{Participants}

In the $T_{1}$ study period, 2032 adolescent patients had at least one attendance at the CAP clinic. Figure 1 demonstrates the participant flow in each stage of the survey. At $T_{1}, n=717$ participated (393 (54.8\%) girls), of whom $n=597$ had a complete diagnostic assessment. At $T_{2}$, all $T_{1}$ participants who previously consented to further inquiry were invited (eligible $n=685$ ), of whom 570 ( $83 \%$ of eligible) completed the follow-up questionnaire, and $549(80 \%)$ completed the diagnostic interview (308 (56.1\%) girls). The present study included participants with complete diagnostic assessment at both $T_{1}$ and $T_{2}(n=464,256(55.2 \%)$ girls), with mean age
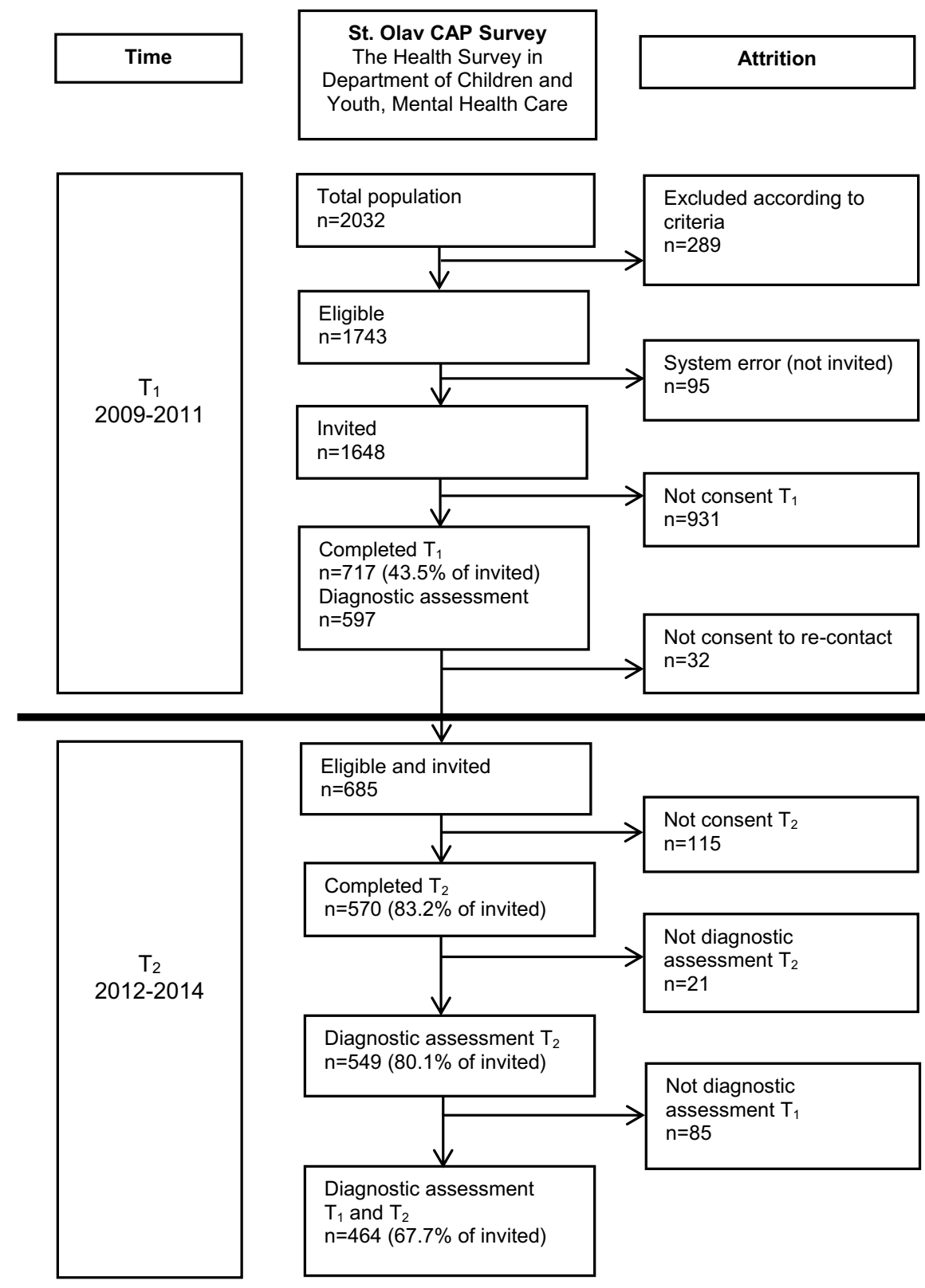

Completed $\mathrm{T}_{1}$

$n=717(43.5 \%$ of invited $)$

Diagnostic assessment $\mathrm{n}=597$

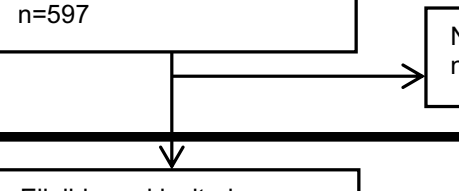

Not consent to re-contact $\mathrm{n}=32$

Eligible and invited $\mathrm{n}=685$

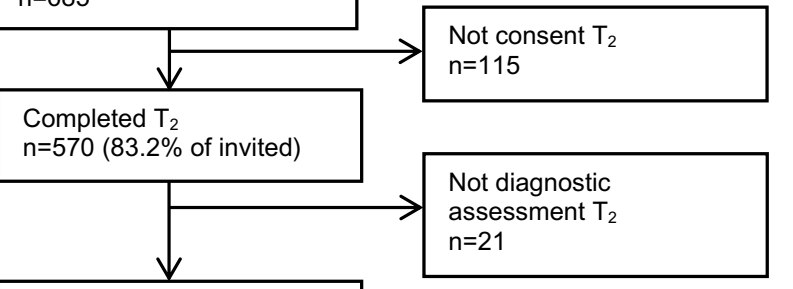

Diagnostic assessment $\mathrm{T}_{2}$ $n=549(80.1 \%$ of invited $)$

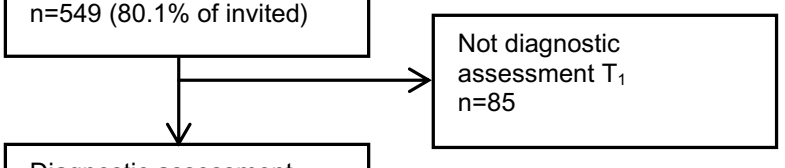

Diagnostic assessment $\mathrm{T}_{1}$ and $\mathrm{T}_{2}$ $n=464(67.7 \%$ of invited $)$ 
at $T_{1}: 15.7$ (range $\left.13.0-20.5\right)$, and at $T_{2}: 18.7(16.0-23.5)$ years (Table 1).

\section{Participants vs. non-participants}

To explore the representativeness of the study population at $T_{1}$, anonymous information about the total clinical population was collected from annual reports from the CAP clinic, 2009-2011. All adolescents in the study period $(n=2032)$ minus those excluded $(n=289)$ were defined as reference population $(n=1743)$. The main reason for referral, age and gender were similar between participants $(n=717,41.1 \%)$ and non-participants $(n=1026,58.9 \%)$ (data not shown). Participants were 0.27 years older: mean (SD) 15.7 (1.7) vs. 15.4 (2.0), and there were more girls among the participants: 393 (54.8\%) vs. 509 (49.6\%). Among those with complete diagnostic assessment at $T_{1}$, there were 464 participants and 133 non-participants at $T_{2}$. Attrition analyses are given in Supplementary Material (Tables S1, S2 and S3). Age, socioeconomic status and frequencies of any psychiatric disorder were similar among participants and non-participants; while, the proportion of girls was higher among participants.

\section{Measures}

Psychiatric diagnoses at $T_{1}$ were set in ordinary clinical practice according to the International Statistical Classification of Disease and Related Health Problems (ICD-10) multiaxial diagnostics (axes I-VI) [30]. The diagnostic process followed standardized procedures for assessment and diagnosis of common adolescent psychiatric disorders, requiring a thorough developmental history and interviews with the adolescents and their parents. For some participants, the semi-structured Schedule for Affective Disorders and Schizophrenia for School-Age Children (K-SADS) [31] was used,for others the Development And Well-Being Assessment (DAWBA) [32], and various rating scales suitable for the presenting problem. The diagnoses were set by a child and adolescent psychiatrist or a clinical psychologist based on all available clinical information, after consensus with other professionals from the multi-disciplinary team. The assessments were supplemented with somatic examination if indicated, and possible coexisting disorders were explored. At $T_{2}$, diagnoses were set using the K-SADS [31] according to the Diagnostic and Statistical Manual of Mental Disorders IV Text revision (DSM-IV-TR) [33]. The interviews were performed with the adolescents by telephone by trained interviewers, all with a graduate degree in medicine or psychology and experience in child and adolescent psychiatric assessment. They met regularly with a supervisor, an experienced child and adolescent psychiatrist, to assure the quality of the diagnostic assessment. All were blinded to $T_{1}$ diagnoses. Inter-rater reliability was assessed using second

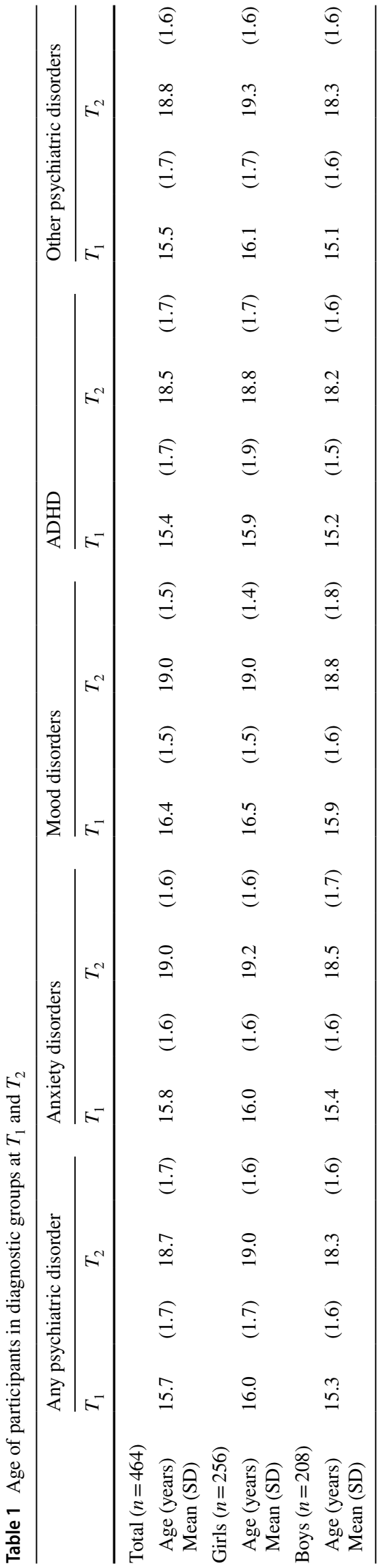


ratings for 28 of the taped telephone interviews. Because of weaknesses of kappa as measure of agreement [34], positive and negative agreement were used as measurement. Positive agreement, as defined by van de Vet et al., varied from 0.615 to 1.000 and, negative agreement varied from 0.884 to 1.000. Details are given in Supplementary Material (Tables S4 and S5).

In the present study, disorders were grouped into the following categories, based on ICD-10 diagnoses at $T_{1}$ and DSM-IV diagnoses at $T_{2}$; any psychiatric disorder, anxiety disorders (ICD-codes F40-F44, F48, F93/DSM-codes 300, 308, 309), mood disorders (ICD-codes F31-F34, F38, F39/DSM-codes 296, 300.4, 311), ADHD (ICD-code F90/ DSM-code 314) and other (ICD-codes F10-F19, F20-F21, F28-F29, F50, F54, F59-F60, F84, F91-F92, F94-F95, F98/DSM-codes 291, 292, 295, 298, 299, 301, 303, 304, $305,307,312,313,316)$. As there were few participants in some diagnostic groups, for example autism and eating disorders, and especially when examining comorbidity, we chose to merge children with these diagnoses into one larger group of other psychiatric disorders for the purpose of this manuscript.

Somatic disorders at $T_{1}$ were registered according to ICD10 axis 4 , set by the medical doctor based on anamnestic information, the entire medical records, including pediatrics, or by clinical investigation. All patients reporting somatic symptoms or disorders had an evaluation by a medical doctor. At $T_{2}$, somatic disorders were recorded as part of the K-SADS interview. Somatic comorbidity was defined as having a psychiatric disorder with a co-occurring somatic disorder requiring regular clinical follow-ups.

Chronic pain $\left(T_{1}\right.$ and $\left.T_{2}\right)$ was defined as the pain not related to any known disease or injury, occurring at least once a week in the last 3 months. The test-retest reliability of questions of pain occurrence at least once a week for the last 3 months has shown to be good [20,35]. As in previous studies, adolescents were asked to fill in a questionnaire and specify if they had experienced headaches, abdominal pain or musculoskeletal pain (e.g., pain in the neck, shoulder, upper and lower extremities, upper back, lower back/seat or chest), accompanied with an illustration of the different locations [20,22]. Multisite pain was defined as having chronic pain in three locations or more [20,22].

Substance use was registered by self-report as smoking, alcohol use and drug use. "Current smokers" included daily or occasional smokers $\left(T_{1}\right.$ and $\left.T_{2}\right)$. "Current alcohol users" included participants, who answered "yes" to the following questions: $T_{1}$ : "Do you sometimes drink alcohol presently?", and $T_{2}$ : "Have you drunk alcohol during the last four weeks?". "Drug use" was indicated by answering "yes" to the question: "Have you ever tried hash, marijuana, or other illicit drugs?" $\left(T_{1}\right.$ and $\left.T_{2}\right)$.
Socioeconomic status (SES) was measured at $T_{1}$ by the mothers' highest level of education, divided into eight categories: (1) less than 9-year primary school; (2) completed 9-year primary school; (3) 1 or 2 years in high school; (4) completed high school; (5) completed high school and 1-year education/training after high school; (6) academy/university for up to and including 4 years; (7) academy/university for 5 years or more; and (8) academy/university including $\mathrm{PhD}$.

\section{Statistical analyses}

The change in point prevalence from $T_{1}$ to $T_{2}$ was based on paired dichotomous data, with Newcombe confidence intervals and the McNemar asymptotic test, as recommended by Fagerland, Lydersen and Laake [36]. We used binary linear regression with psychiatric disorder at $T_{2}$ as dependent variable and relevant variables at $T_{1}$, one at a time, to study their associations. Effects of age and SES as possible confounders were explored. We reported $95 \%$ confidence intervals (CI) where relevant, and two-sided $p$ values $<0.05$ were considered statistically significant. Binary regression was performed in Stata 15, Newcombe CI and McNemars test were calculated in Excel, and the rest in SPSS 25.

\section{Ethics}

Written informed consent was obtained from adolescents and parents prior to inclusion at $T_{1}$, and from the adolescents at $T_{2}$, according to study procedures. Study approval was given by the Regional committee for Medical and Health Research Ethics (reference numbers CAP survey $T_{1}$ : 4.2008.1393, $T_{2}:$ 2011/1435/REK Midt, and present study using $T_{1}$ and $T_{2}$ data: 2017/589/REK Midt). The Norwegian Social Science Data Services, The Data Protection Official for Research, gave permission to compare the main reason for referral, age and sex between participants and non-participants in connection with inclusion at baseline (reference number CAP survey: 19976).

\section{Results}

\section{Psychiatric disorders and comorbidity}

The overall rate of diagnoses decreased from $94.8 \%$ at $T_{1}$ to $72.2 \%$ at $T_{2}$. The change [risk difference; $\mathrm{RD}=-22.6 \%$, CI $(-26.9,-18.5), p<0.001]$ was present in both genders (Table 2). However, the frequency of anxiety disorders increased in the total sample [31.7\% vs. $40.1 \%, \mathrm{RD}=8.4 \%$, CI $(2.7,14.0), p=0.004]$, but among girls only [37.5\% vs. $55.9 \%, \mathrm{RD}=18.4 \%$, CI $(10.1,26.3), p<0.001]$. Psychiatric comorbidity increased in any psychiatric disorder [28.0\% vs. $36.4 \%, \mathrm{RD}=8.4 \%, \mathrm{CI}(2.8,13.9), p=0.003]$, but for 


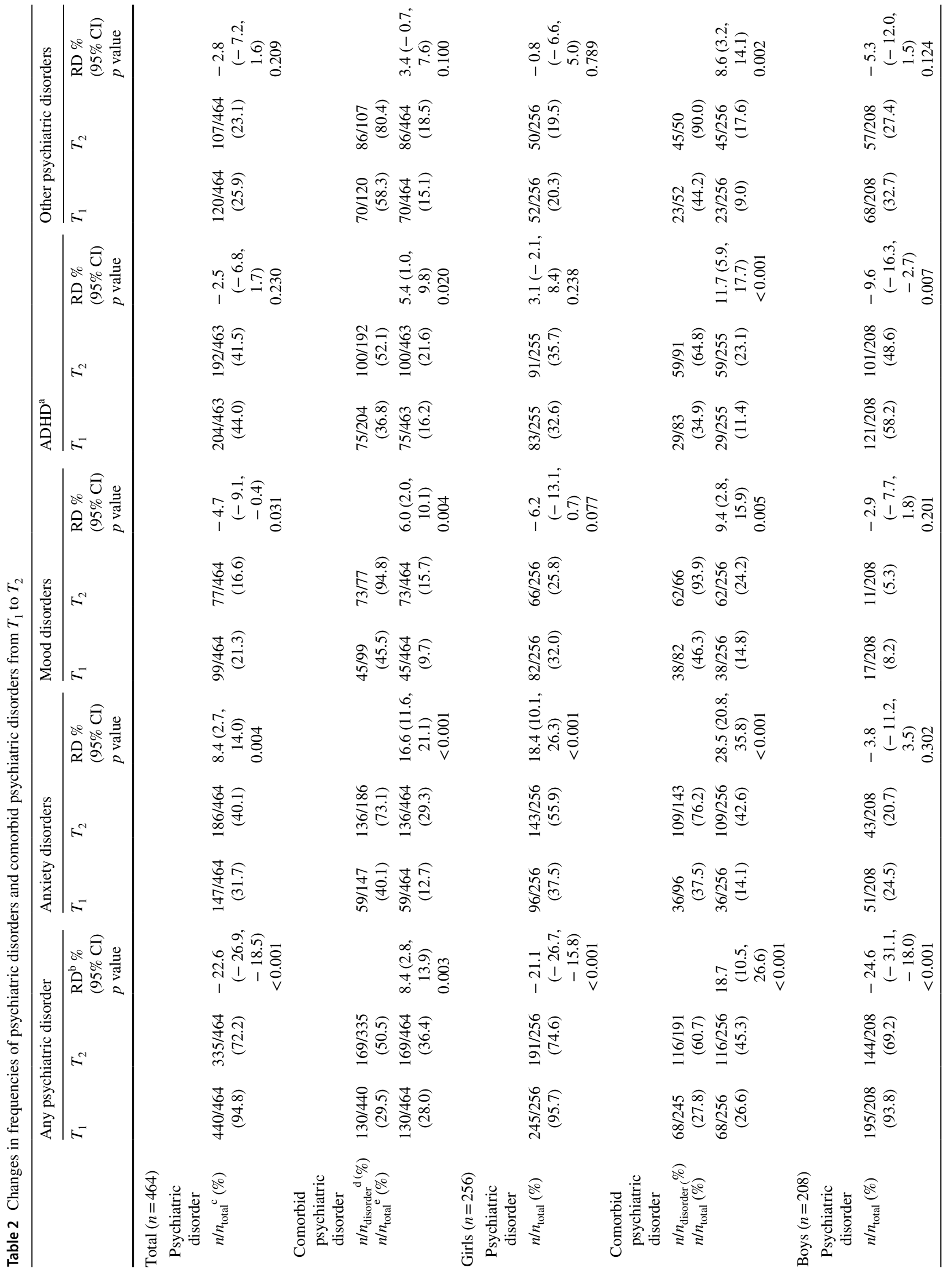




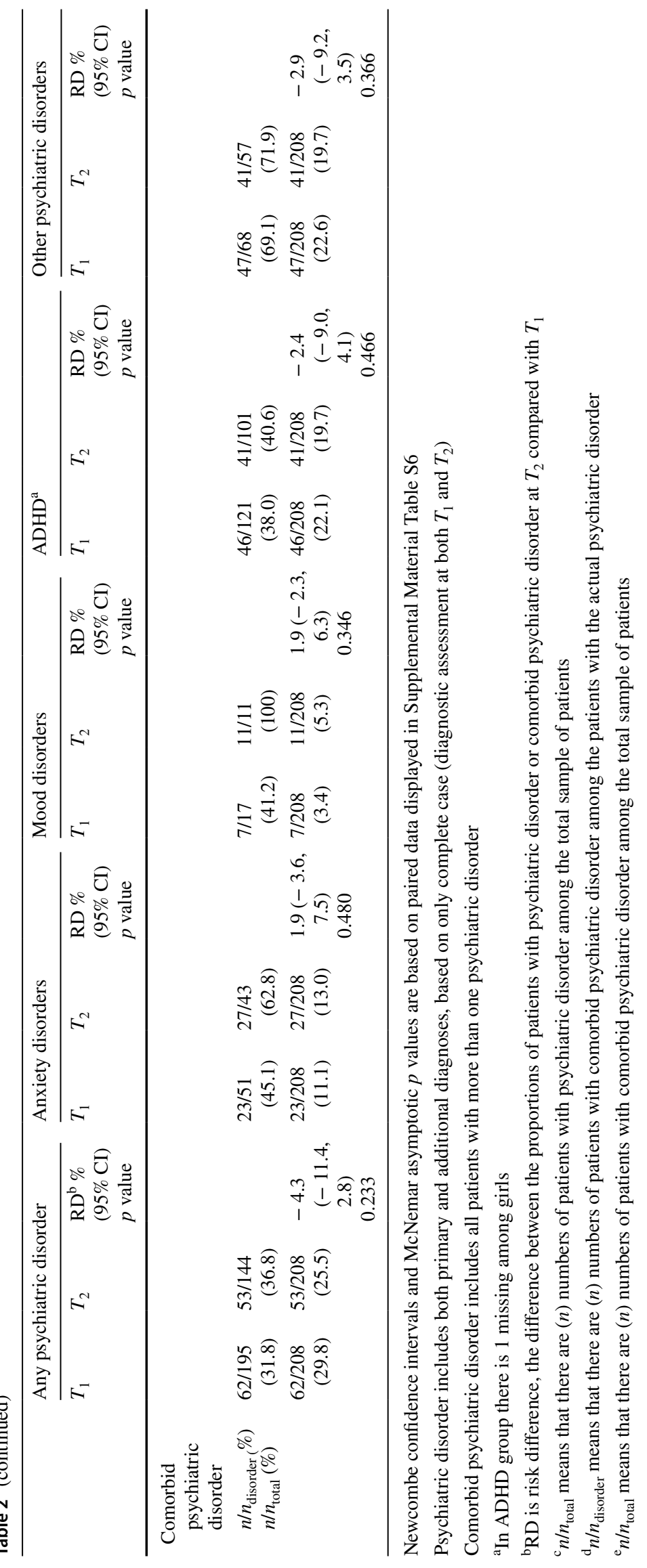


girls only [ $26.6 \%$ vs. $45.3 \%, \mathrm{RD}=18.7 \%$, CI $(10.5,26.6)$, $p<0.001]$. The increase in psychiatric comorbidity in the total sample was statistically significant in anxiety disorders, mood disorders and ADHD, and in all diagnostic subgroups for girls, but not for boys (Table 2).

\section{Somatic comorbidity and chronic pain}

Somatic comorbidity increased in frequency in the anxiety disorder group $[7.1 \%$ vs. $12.7 \%, \mathrm{RD}=5.6 \%, \mathrm{CI}(2.0$, 9.3), $p=0.003]$, but only among girls $[9.4 \%$ vs. $19.5 \%$, $\mathrm{RD}=10.1 \%$, CI $(4.3,16.1), p=0.001]$ (Table 3). For other psychiatric disorders, somatic comorbidity remained unchanged in both genders. The prevalence of chronic pain in the cohort was high, but decreased overall in the total sample [65.8\% vs. $49.3 \%, \mathrm{RD}=-16.5 \%$, CI $(-21.0$, $-11.0), p<0.001]$, and for both girls and boys. However, chronic pain increased among patients with anxiety disorders [ $23.3 \%$ vs. $31.8 \%, \mathrm{RD}=8.5 \%$, CI $(3.1,13.7), p=0.002]$, but the increase was found only among girls $[31.6 \%$ vs. $49.4 \%, \mathrm{RD}=17.9 \%$, CI $(9.5,25.4), p<0.001]$. At $T_{2}$, girls with anxiety disorders had a higher rate of chronic pain than boys with these disorders ( $88.7 \%$ vs. $48.8 \%)$, and also a higher rate of multisite pain ( $66.2 \%$ vs. $20.9 \%)$. The diagnostic group with highest frequencies of chronic pain was mood disorders for both girls (96.9\%) and boys (72.7\%). The frequencies of multisite pain were also highest in this diagnostic group.

\section{Substance use}

The amount of substance use changed during the 3-year follow-up (Table 4). There was a non-significant reduction in smoking $[30.3 \%$ vs. $19.6 \%, \mathrm{RD}=-10.6 \%$, CI $(-10.4$, $0.5), p=0.074]$ in the total sample, but smoking increased for anxiety disorders $[\mathrm{RD}=4.5 \%$, CI $(2.0,9.2), p=0.002]$, and only among girls. Alcohol use increased for anxiety disorders and ADHD in the total sample $[\mathrm{RD}=10.5 \%, \mathrm{CI}(6.3$, 16.3), $p<0.001$, and $\mathrm{RD}=7.0 \%$, CI $(3.6,13.1), p<0.001$, respectively], and among girls with these disorders. Trying illicit drugs increased overall, in both genders, and in all diagnostic subgroups for girls, with the highest increase in the anxiety group [ $4.7 \%$ vs. $22.4 \%, \mathrm{RD}=17.7 \%, \mathrm{CI}(12.8$, $23.7), p<0.001]$. Among boys, an increase was seen in the ADHD group [6.3\% vs. $15.1 \%, \mathrm{RD}=8.8 \%$, CI $(5.6,15.1)$, $p<0.001]$ and in the group of other psychiatric disorders.

\section{Analysis of associations}

Binary linear regression including age or SES as covariate showed no association with persistence of psychiatric disorder, i.e., no confounding effects were found either in the total sample or separately for each gender (Table 5).
There was an association between having chronic pain at $T_{1}$ and persisting psychiatric disorder for the total sample $[\mathrm{RD}=17.2 \%$, CI $(7.9,26.6), p<0.001]$, and most evident for girls $[\mathrm{RD}=25.4 \%$, CI $(9.6,41.2), p=0.002]$ (Table 4). Associations were also found between smoking and trying illicit drugs and persisting psychiatric disorders among girls $[\mathrm{RD}=15.6 \%$, CI $(4.1,27.0), p=0.008$, and $\mathrm{RD}=18.0 \%$, CI (7.3, 28.6), $p=0.001$, respectively].

\section{Discussion}

This study is one of the few surveys studying the development of psychiatric disorders and comorbidity over time, following a general clinical psychiatric population of adolescents who received standard clinical care. While the general psychiatric morbidity decreased in the course of 3 years, including mood disorders, the rate of anxiety disorders increased, and having more than one psychiatric disorder became more frequent. Altogether, three out of four still had a psychiatric disorder. The most prominent finding was the marked increase of anxiety disorders among girls, accompanied by more psychiatric comorbidity, somatic comorbidity and chronic pain; whereas boys had decreased morbidity overall. Substance use was prevalent among girls with anxiety disorders, while trying illicit drugs clearly involved the most marked increase in both genders. Chronic pain, smoking and trying illicit drugs at the first visit were associated with persisting psychiatric disorders, with highest risk difference for girls.

The reasons for the high rates of persisting disorders may be diverse, both depending on the treatment given and the general vulnerability in the adolescents in this clinical population, who have a high disease burden. In a study of Copeland et al., investigating the cumulative prevalence of psychiatric disorders in young adulthood among 1420 participants assessed between ages 9 and 21, they found that $61.1 \%$ met DSM criteria for a well-specified psychiatric disorder by 21 years of age, indicating that many struggle with mental health problems in young adulthood [37]. There is an increase in overall rates of psychiatric disorders in the transition from adolescence to adulthood [7]. Common psychiatric disorders in adolescence are often forerunners and strong predictors of similar disorders in young adulthood, and most young adults with episodes of a psychiatric disorder have had episodes during their teenage years [7, 8, 28, 29], which is in accordance with the findings by Ranøyen et al. in the CAP Survey [38]. Kim-Cohen et al. found that among those who met criteria for a major DSM diagnosis at 26 years, half had a disorder at age 11-15 years, and three out of four before 18 years [39]. The higher frequency among girls overall, and especially in girls with anxiety disorders, is comparable with the earlier research $[11,40]$. Results from the 


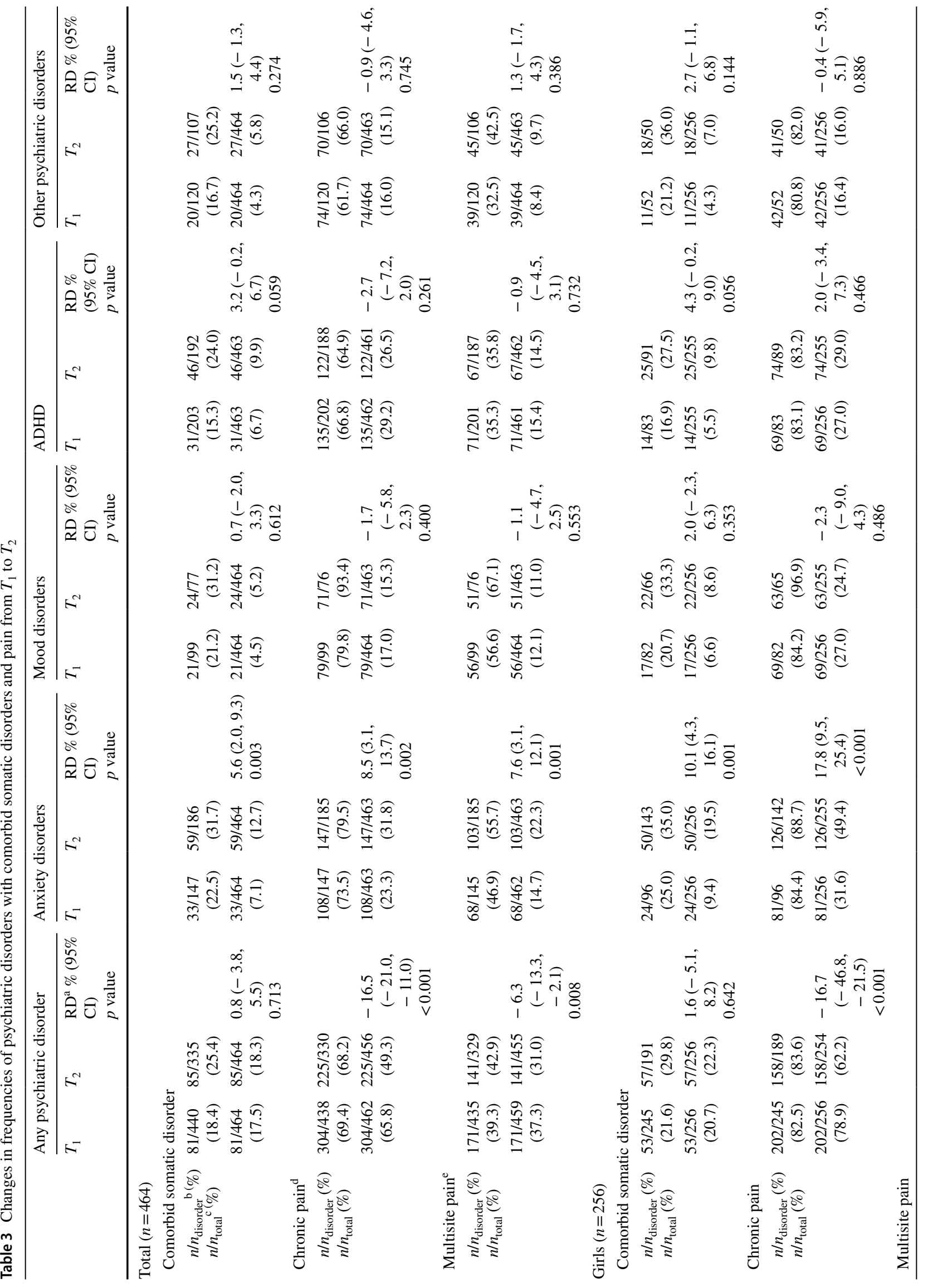




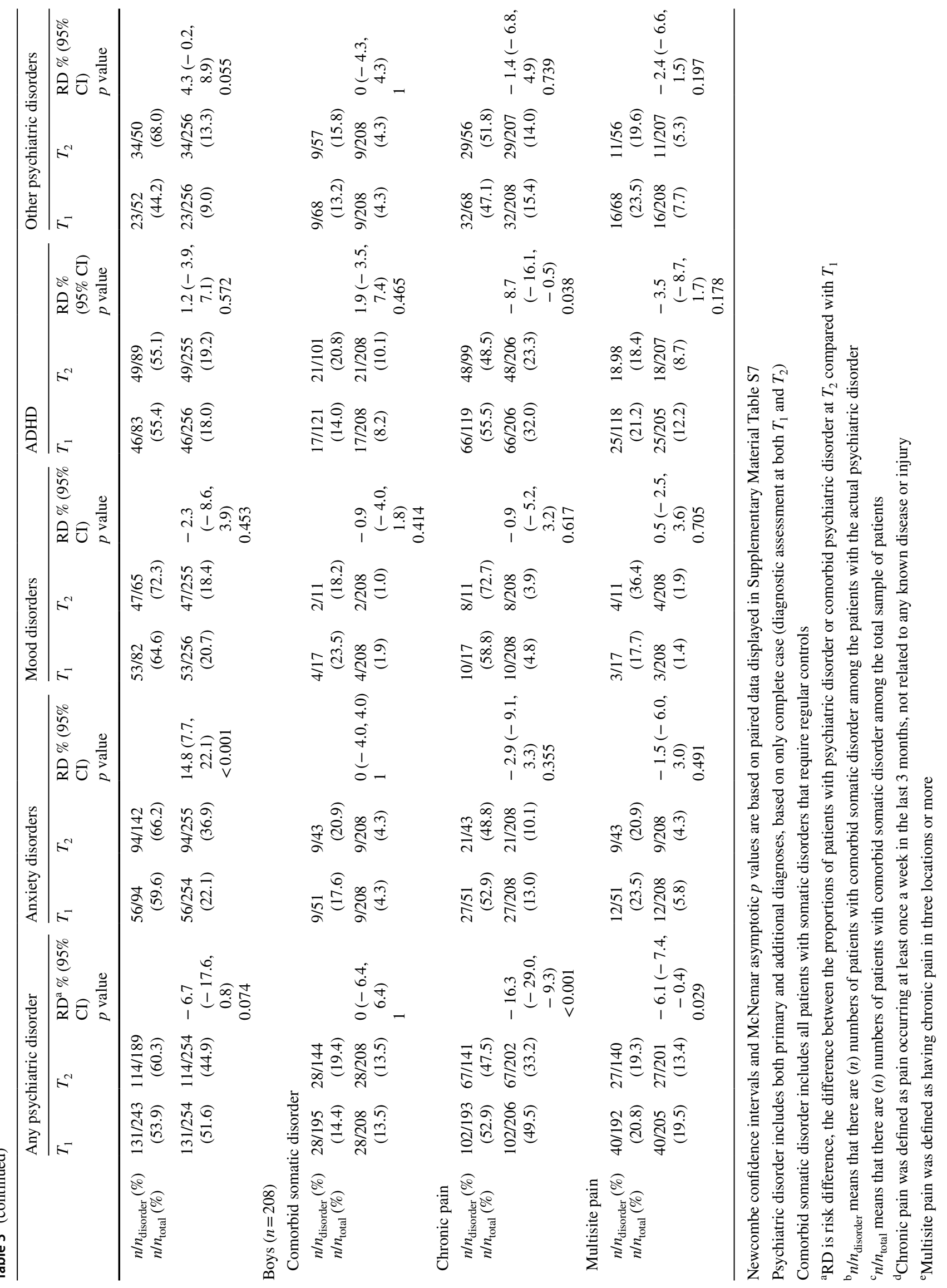




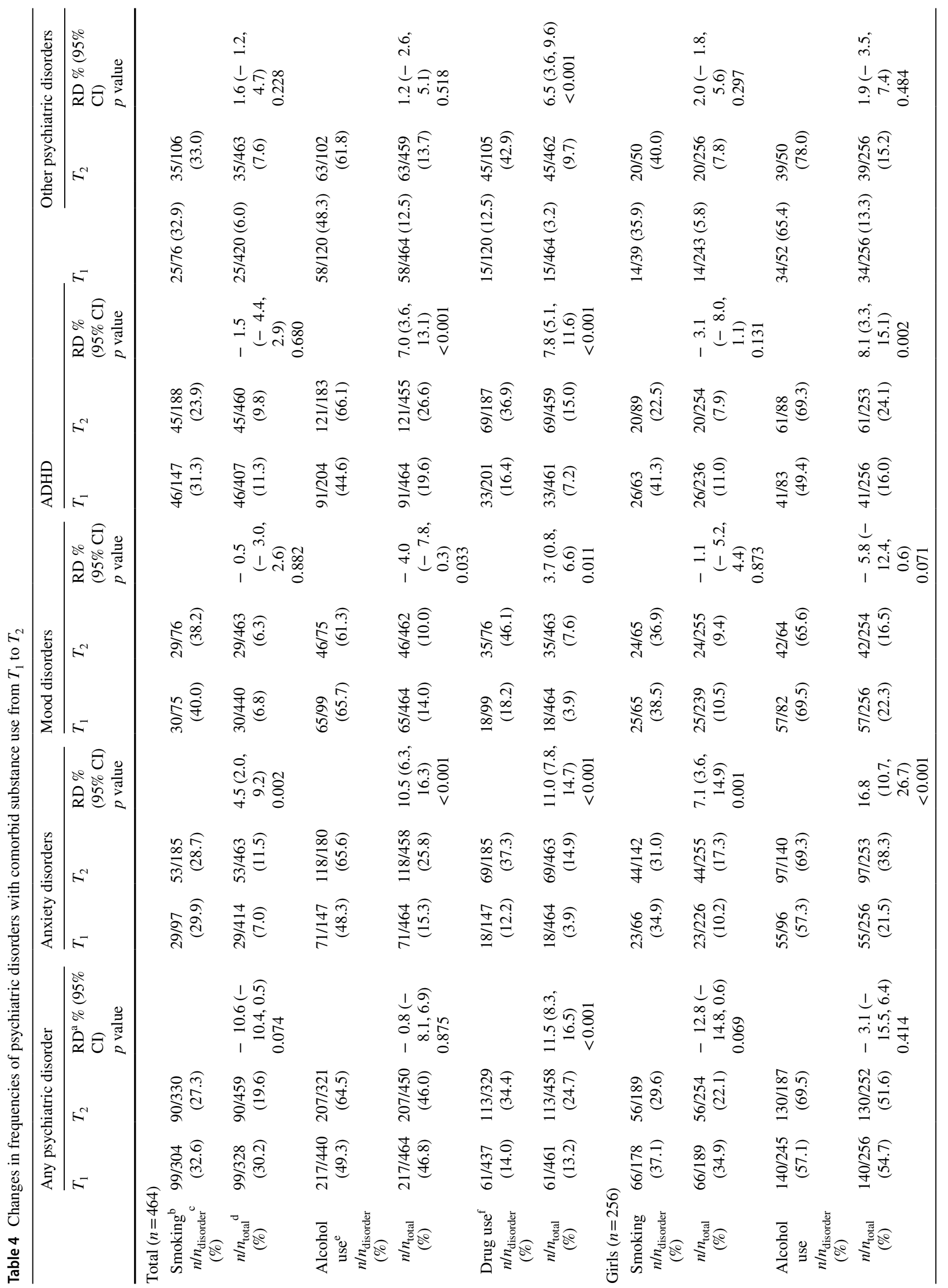




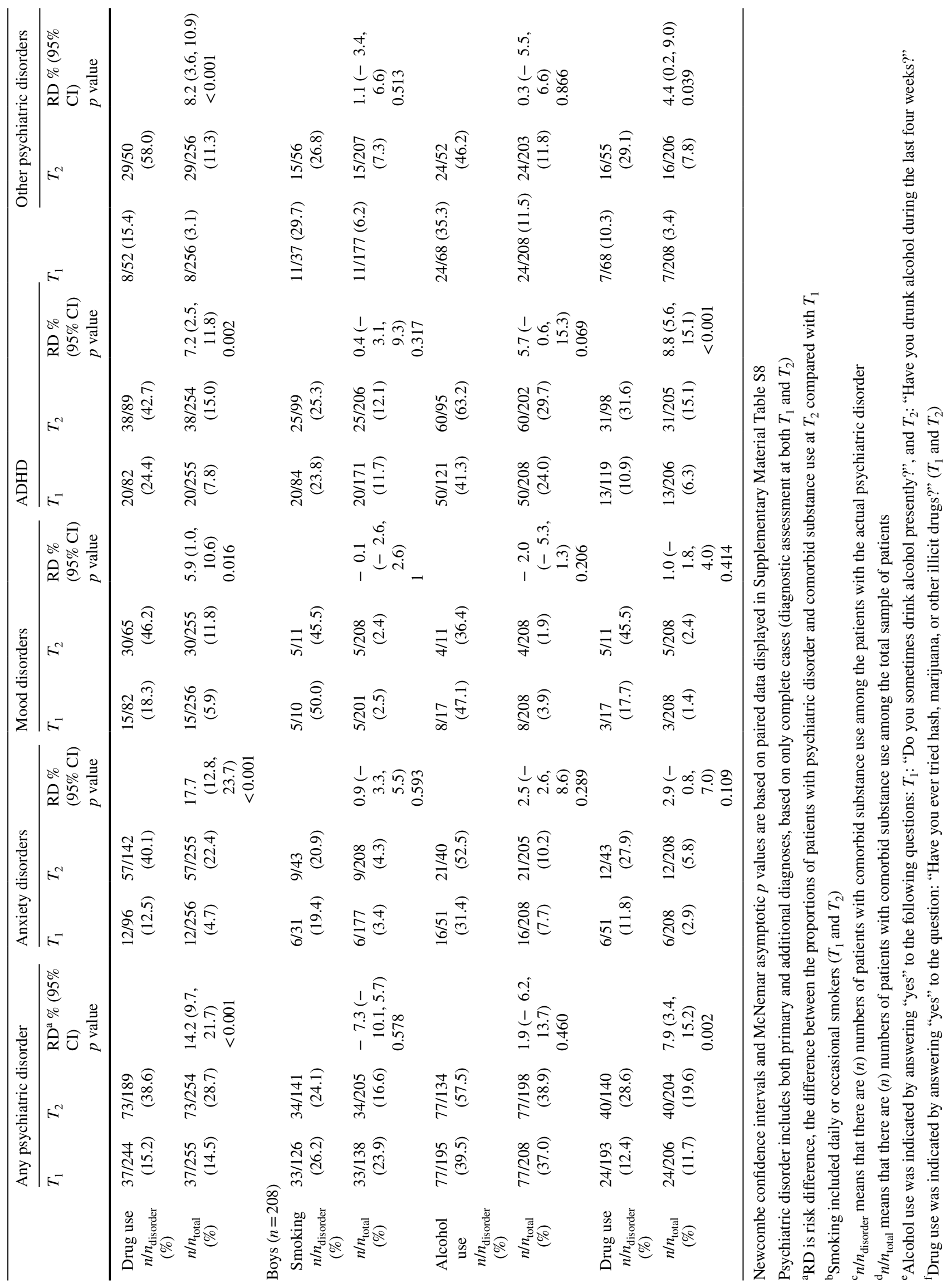


Table 5 Binary linear regression with psychiatric disorder at $T_{2}$ as dependent variable, and the listed covariates one at a time

\begin{tabular}{|c|c|c|c|c|c|c|c|}
\hline \multirow[t]{3}{*}{ Co-variable at $T_{1}$} & \multirow[t]{3}{*}{$n$} & \multicolumn{6}{|c|}{ Any psychiatric disorder $T_{2}$} \\
\hline & & \multirow{2}{*}{$\begin{array}{l}\text { Co-variable } T_{1} \mathrm{NO} \\
n(\%)\end{array}$} & \multirow{2}{*}{$\begin{array}{l}\text { Co-variable } T_{1} \text { YES } \\
n(\%)\end{array}$} & \multirow[t]{2}{*}{$\mathrm{RD}^{\mathrm{a}} \%$} & \multicolumn{2}{|c|}{ 95\% CI for $\mathrm{RD}$} & \multirow[t]{2}{*}{$p$ value } \\
\hline & & & & & Lower & $\overline{\text { Upper }}$ & \\
\hline Total sample & 440 & & & & & & \\
\hline Chronic pain & 438 & $84 / 134(62.7)^{\mathrm{b}}$ & 243/304 (79.9) & 17.2 & 7.9 & 26.6 & $<0.001$ \\
\hline Any somatic disorder & 440 & $269 / 359(74.9)$ & $59 / 81(72.8)$ & -2.1 & -12.8 & 8.6 & 0.701 \\
\hline Smoking & 304 & $151 / 205(73.7)$ & $84 / 99(84.8)$ & 11.2 & 1.9 & 20.5 & 0.018 \\
\hline Alcohol use & 440 & $160 / 224(71.4)$ & $168 / 216(77.8)$ & 6.3 & -1.8 & 14.5 & 0.125 \\
\hline Drug use & 437 & $272 / 376(72.3)$ & $54 / 61(88.5)$ & 16.2 & 7.0 & 25.4 & 0.001 \\
\hline Age & 440 & & & $0.105^{\mathrm{c}}$ & -2.39 & 2.60 & 0.934 \\
\hline SES & 326 & & & $0.012^{\mathrm{d}}$ & -2.82 & 2.80 & 0.993 \\
\hline Girls & 245 & & & & & & \\
\hline Chronic pain & 245 & $24 / 43(55.8)$ & $164 / 202(81.2)$ & 25.4 & 9.6 & 41.2 & 0.002 \\
\hline Any somatic disorder & 245 & 149/192 (77.6) & $39 / 53(73.6)$ & -4.0 & -17.3 & 9.3 & 0.553 \\
\hline Smoking & 178 & $81 / 112(72.3)$ & $58 / 66(87.9)$ & 15.6 & 4.1 & 27.0 & 0.008 \\
\hline Alcohol use & 245 & $78 / 105(74.3)$ & $110 / 140(78.6)$ & 4.3 & -6.5 & 15.1 & 0.437 \\
\hline Drug use & 244 & 153/207 (73.9) & $34 / 37$ (91.9) & 18.0 & 7.3 & 28.6 & 0.001 \\
\hline Age & 245 & & & 0.200 & -3.21 & 3.61 & 0.908 \\
\hline SES & 177 & & & 0.797 & -4.58 & 2.98 & 0.680 \\
\hline Boys & 195 & & & & & & \\
\hline Chronic pain & 193 & 60/91 (65.9) & $79 / 102(77.5)$ & 11.5 & -1.2 & 24.2 & 0.076 \\
\hline Any somatic disorder & 195 & $120 / 167(71.9)$ & $20 / 28(71.4)$ & -0.4 & -18.5 & 17.7 & 0.963 \\
\hline Smoking & 126 & 70/93 (75.3) & $26 / 33(78.8)$ & 3.5 & -13.0 & 20.1 & 0.677 \\
\hline Alcohol use & 195 & $82 / 119(68.9)$ & $58 / 76(76.3)$ & 7.4 & -5.3 & 20.1 & 0.253 \\
\hline Drug use & 193 & $119 / 169(70.4)$ & $20 / 24(83.3)$ & 12.9 & -3.5 & 29.4 & 0.124 \\
\hline Age & 195 & & & 0.881 & -4.78 & 3.01 & 0.657 \\
\hline SES & 149 & & & 0.944 & -3.24 & 5.13 & 0.659 \\
\hline
\end{tabular}

${ }^{a} \mathrm{RD}$ is risk difference, the difference between the proportions of patients with persistent psychiatric disorder and co-variable present at $T_{1}$ compared with patients with persistent psychiatric disorder without present co-variable at $T_{1}$

${ }^{\mathrm{b}}$ The numbers in this table, for example 84/134 (62.7) and 243/304 (79.9), indicate that among the 134 patients with a psychiatric disorder and no chronic pain at $T_{1}, 84$ had a psychiatric disorder at $T_{2}$, and among the 304 patients with a psychiatric disorder and chronic pain at $T_{1}, 243$ had a psychiatric disorder at $T_{2}$

${ }^{\mathrm{c}}$ The risk of having a persistent psychiatric disorder increases with $0.105 \%$ per one year increase of age

${ }^{\mathrm{d}}$ The risk of having a persistent psychiatric disorder increases with $0.012 \%$ per one unit change in level of mothers education

Child/Adolescent Anxiety Multimodal Extended Long-Term Study (CAMELS) found that despite receiving high-quality evidence-based treatments for anxiety, only $22 \%$ were in stable remission across all 4 years they were assessed, $30 \%$ were chronically ill, and $48 \%$ experienced relapses [41]. In this study, male gender was associated with increased probability of being in the remission group compared to the relapser group, supporting our finding of higher morbidity among girls. Mood disorders had decreased at follow-up and may have been under-registered in this study. As the course of such disorders is fluctuating, present status may not reflect struggling with periodic disorders.

The female patients seemed to be more prone to develop co-occurring psychiatric disorders. This corresponds well with the previous studies reporting more comorbidity in girls than boys [10, 42]. In our sample, girls had very high rates of psychiatric comorbidity at follow-up, in all diagnostic groups, and highest among those with mood disorders, where more than nine out of ten had an additional psychiatric disorder. All boys with mood disorders also had a comorbid psychiatric disorder, but since there were few boys with mood disorders, the change in frequencies were small. Also, somatic comorbid diagnoses became more frequent for female patients with anxiety disorders. An increased risk of somatic disorders is reported in patients with anxiety disorders [43], independent of gender. Furthermore, adolescents who experience chronic somatic health conditions, are found to be at risk of elevated physiological anxiety symptoms in mid-adolescence [44]. The higher frequency of girls than boys with anxiety disorders in our sample may have 
influenced the finding of a significant increase only among female patients. Still, the results show consistently that the burden of disease was most prominent among girls.

Overall, there was a decrease in chronic pain for the total sample after 3 years, but an increase among those with anxiety disorders, not surprisingly since chronic pain may be regarded as part of the anxiety disorder. We found large differences in frequency of pain between the genders at $T_{2}$. Nearly, nine out of ten girls and five out of ten boys with anxiety disorders had chronic pain, and the frequency of multisite pain was more than three times as high in girls with anxiety disorders compared to boys. A systematic review investigating the epidemiology of chronic pain in children and adolescents from the general population found that pain prevalence was generally higher in girls and increased with age for most pain types [45]. Using data from a large Norwegian population study, Skrove et al. demonstrated higher prevalence of chronic multisite pain among adolescent girls and boys with increasing number of psychiatric symptoms, but with highest rates among girls [46]. In the St. Olav CAP Survey at $T_{1}, 70 \%$ of the patients reported chronic pain in addition to a psychiatric disorder [21]. This was a higher frequency than the $44 \%$ reported in the general adolescent population in many countries [47] and in our region [22], and underlines the importance of assessing chronic pain among adolescents with psychiatric symptoms and disorders.

Norway appears to be a low-prevalence country when it comes to substance use in the general adolescent population in comparison with other European countries [48]. At $T_{1}$, the adolescents reported a higher intake of alcohol, a higher prevalence of smoking, and a four times higher ratio of having tried illicit drugs compared to the general population [24]. In our sample, smoking tended to decrease during follow-up, with no gender differences; whereas, alcohol use did not change substantially overall, but increased for anxiety disorders and ADHD in the total sample and for girls. Some increase was expected, since the age of participants increased from 13-18 years to 16-21 years, and drinking alcohol is more common at these ages. Also, young adults are allowed to buy alcohol in Norway from 18 years. Finding the highest increase among girls with anxiety disorders corresponds well with earlier Norwegian studies [26, 49].

The more surprising result was the significantly increased level of having tried illicit drugs in all diagnostic categories, and especially in the female sample. Getting correct information using self-report on behavior that may be shameful or illegal, may be a challenge. Therefore, the reports on drug use must be interpreted with caution. During adolescence, there is a general increased use of illicit drugs and a possible increased tolerance, which can contribute to an increased incidence 3 years later [50]. Still, associations with the specific psychiatric disorders are relevant. We found highest rates among girls with anxiety disorders; in this group, one out of five had tried illicit drugs. There are inconsistent findings on the association between anxiety disorders and alcohol/drug use in previous studies, some indicating a positive association [51], and other demonstrating negative associations [52]. Opposite to our finding, Turner et al. demonstrated in a review that self-medication with alcohol or drugs for mood and anxiety disorders was associated with male gender [53]. A recent population-based study showed gender-specific substance use patterns among Portuguese adolescents [54]. We found increasing rates of illicit drug use among patients with ADHD for both genders, which corresponds with recent findings from the MTA longitudinal study [55]. Our results and the inconsistent findings between studies indicate the need for further research on gender and disorder-specific substance use in a clinical population.

We examined the possible risk factors associated with the persistence of psychiatric disorders. There was a significant association between having chronic pain at $T_{1}$ and persisting psychiatric disorder over 3 years for the total sample, and strongest in the female group. Earlier studies have demonstrated associations between pain in adolescence and mental health problems in young adulthood $[18,19]$. Presence of chronic pain in adolescents with psychiatric disorders, especially among girls, is, therefore, important to assess, since these patients seem to be vulnerable for persistent and even increasing psychiatric morbidity. There was also an association between smoking or having tried illicit drugs and persistence of psychiatric morbidity in girls. Socioeconomic status as measured by maternal level of education could not explain the persistence of disorders or the effect of these risk factors, nor could participants' age.

The strength of the present study is the inclusion of a large clinical sample, providing a high degree of precision in the estimates, and the response rate from $T_{1}$ to $T_{2}$ was high. Although the attrition rate was high in the initial recruitment, the $T_{1}$ sample did not differ in age, gender or reason for referral compared to non-participants. This high attrition rate may still have affected the results, and both severity of symptoms and types of treatment may have played a role in in the continuity of a disorder and for participation at follow-up. The number of participants was low for some diagnostic groups which probably limits the generalizability of the results. Furthermore, due to few participants in some diagnostic groups, especially when examining comorbid chronic pain, somatic disorders and substance use, we chose to merge children with these diagnoses into one larger group.

The psychiatric diagnoses were classified by clinicians, according to the current diagnostic classification systems, and not based on the self-report measures which involves the limitations of less accuracy in establishing psychopathology. However, two different classification systems were used at the two time points, which may have affected prevalence rates and is a possible limitation. Research has shown that 
the concordance between the two systems can differ across the range of disorders, and with varying concordance within the anxiety disorders [56], and also the diagnostic criteria for hyperkinetic disorder in ICD-10 are more strict than the criteria for ADHD in DSM-IV. In particular, this may have contributed to a higher increase in ADHD diagnosis at follow-up. Beyond that, the ICD-10 and DSM-IV are widely harmonized. The classification process differed between the two time points; At $T_{1}$, diagnoses were based on all available clinical information collected by the multi-disciplinary team, and at $T_{2}$, the acknowledged K-SADS semi-structured interview was performed as telephone interview. This may also have affected the diagnostic accuracy. K-SADS assesses all psychiatric disorders more systematically, which could have led to reporting more comorbid disorders at $T_{2}$, even though secondary disorders were stated on the basis of thorough assessment also at $T_{1}$. It is also reasonable to assume that some differences in diagnoses over time might be explained by the different methods and diagnostic procedures between the two time points. There is no well-established definition of chronic pain in children, but the definitions of chronic pain and multisite pain used in this study are widely used in other epidemiologic pain studies, and have been used in the general population in studies from the same area [20, 22]. Still, some information bias cannot be excluded when using self-reports, which could lead to an under- or overestimation of chronic pain and substance use. There was different wording in the question about alcohol use at the two time points. Trying illicit drugs was reported only by one question, and although the same question was used at both time points, this topic may be especially prone to information bias. Using level of maternal education to indicate socioeconomic status may not encircle the entire concept of SES, and furthermore, the SES information was available in a reduced sample, which may not reflect the total study population. Treatment plausibly impact the course of morbidity, and the lack of treatment assessment in this study is a limitation. Since there were more girls than boys among participants compared to non-participants in this study, we may have lost some of the boys with psychiatric disorders.

\section{Clinical implications}

The results of this study bring an important message to clinical practice. Even though clinicians know about mental health challenges in adolescence, the persistence of psychiatric disorders over 3 years from early to late adolescence should be an extra eye-opener, and especially the increased rate of anxiety disorders and comorbidities among girls. The burden of disease in this age group must be acknowledged. In-depth assessment of mental health problems should of course include important risk factors, and asking adolescent patients about pain, uncover smoking habits and illicit drug use seems to be essential, especially for female patients. Providing standard clinical care may not be enough, as these risk factors point to the need for intensified psychiatric treatment to prevent persistence of the psychiatric disorders. Furthermore, long-term clinical follow-up should be considered for adolescents with risk factors.

\section{Conclusions}

Psychiatric morbidity decreased over 3 years in this adolescent clinical sample, including mood disorders, but nevertheless, almost three out of four still had a psychiatric disorder. The high frequency of psychiatric and somatic comorbidity, and chronic pain, indicates generally a high burden of disease, and chronic pain may be seen as part of the complexity of psychiatric disorders, especially anxiety disorders. Female adolescents seemed to have a higher morbidity than male adolescents, with an increased frequency of anxiety disorders after 3 years, and a five-ten times higher prevalence of chronic pain than boys. Chronic pain, smoking and having tried illicit drugs at baseline were factors strongly associated with persistent psychiatric morbidity. Although some differences in diagnoses over time might be explained by the different methods and diagnostic procedures between the two time points, the results indicate the need for addressing the associated factors and include them in a comprehensive follow-up of psychiatric disorders in this age group.

Acknowledgements Open Access funding provided by NTNU Norwegian University of Science and Technology (incl St. Olavs Hospital - Trondheim University Hospital). This study was financed by a PhD grant awarded to the first author by The Liaison Committee for education, research and innovation in Central Norway. The Health Survey in Department of Children and Youth, Division of Mental Health Care, St. Olavs hospital, Trondheim University Hospital, Norway (St. Olav CAP Survey), is a product of professional and financial collaboration between St. Olavs hospital-Trondheim University Hospital, and the Regional Centre for Child and Youth Mental Health and Child Welfare, Department of Mental Health, Faculty of Medicine and Health Sciences, Norwegian University of Science and Technology (NTNU). Additional funding was assigned from The Liaison Committee for education, research and innovation, Central Norway $\left(T_{1}\right)$ and from the Joint Research Committee between St. Olavs hospital and Faculty of Medicine and Health Sciences, NTNU $\left(T_{2}\right)$. The authors wish to acknowledge research assistant Anne Regine Sveen for coordinating data collection $\left(T_{2}\right)$, and a special gratitude is extended to the adolescents participating in the CAP survey.

\section{Compliance with ethical standards}

Conflict of interest The authors declare that they have no conflict of interest.

Ethical approval This study has been approved by the Regional committee for Medical and Health Research Ethics of Central Norway and 
comply with the ethical standards in the Declaration of Helsinki from 1964 and later amendments.

Open Access This article is licensed under a Creative Commons Attribution 4.0 International License, which permits use, sharing, adaptation, distribution and reproduction in any medium or format, as long as you give appropriate credit to the original author(s) and the source, provide a link to the Creative Commons licence, and indicate if changes were made. The images or other third party material in this article are included in the article's Creative Commons licence, unless indicated otherwise in a credit line to the material. If material is not included in the article's Creative Commons licence and your intended use is not permitted by statutory regulation or exceeds the permitted use, you will need to obtain permission directly from the copyright holder. To view a copy of this licence, visit http://creativecommons.org/licenses/by/4.0/.

\section{References}

1. Achenbach TM, Rescorla LA, Ivanova MY (2012) International epidemiology of child and adolescent psychopathology I: diagnoses, dimensions, and conceptual issues. J Am Acad Child Adolesc Psychiatry 51(12):1261-1272. https://doi.org/10.1016/j. jaac.2012.09.010

2. Polanczyk GV, Salum GA, Sugaya LS, Caye A, Rohde LA (2015) Annual research review: a meta-analysis of the worldwide prevalence of mental disorders in children and adolescents. J Child Psychol Psychiatry 56(3):345-365. https://doi.org/10.1111/ jcpp. 12381

3. Mykletun AKA, Mathiesen KS (2009) Psykiske lidelser i Norge: Et folkehelseperspektiv [Mental disorders in Norway: a public health perspective]. Norwegian Institute of Public Health, Norwegian

4. Heiervang E, Stormark KM, Lundervold AJ, Heimann M, Goodman R, Posserud MB, Ullebo AK, Plessen KJ, Bjelland I, Lie SA, Gillberg C (2007) Psychiatric disorders in Norwegian 8to 10-year-olds: an epidemiological survey of prevalence, risk factors, and service use. J Am Acad Child Adolesc Psychiatry 46(4):438-447. https://doi.org/10.1097/chi.0b013e31803062bf

5. Van Roy B, Grøholt B, Heyerdahl S, Clench-Aas J (2006) Selfreported strengths and difficulties in a large Norwegian population 10-19 years. Eur Child Adoles Psy 15(4):189-198

6. de Girolamo G, Dagani J, Purcell R, Cocchi A, McGorry PD (2012) Age of onset of mental disorders and use of mental health services: needs, opportunities and obstacles. Epidemiol Psychiatr Sci 21(1):47-57

7. Costello EJ, Copeland W, Angold A (2011) Trends in psychopathology across the adolescent years: what changes when children become adolescents, and when adolescents become adults? J Child Psychol Psychiatry 52(10):1015-1025. https://doi.org/10 $.1111 / \mathrm{j} .1469-7610.2011 .02446 . x$

8. Patton GC, Coffey C, Romaniuk H, Mackinnon A, Carlin JB, Degenhardt L, Olsson CA, Moran P (2014) The prognosis of common mental disorders in adolescents: a 14-year prospective cohort study. Lancet (London, England) 383(9926):1404-1411. https://doi.org/10.1016/s0140-6736(13)62116-9

9. Gore FM, Bloem PJ, Patton GC, Ferguson J, Joseph V, Coffey C, Sawyer SM, Mathers CD (2011) Global burden of disease in young people aged 10-24 years: a systematic analysis. Lancet (London, England) 377(9783):2093-2102. https://doi. org/10.1016/s0140-6736(11)60512-6

10. Costello EJ, Mustillo S, Erkanli A, Keeler G, Angold A (2003) Prevalence and development of psychiatric disorders in childhood and adolescence. Arch Gen Psychiatry 60(8):837-844. https://doi. org/10.1001/archpsyc.60.8.837

11. Merikangas KR, He JP, Burstein M, Swanson SA, Avenevoli S, Cui L, Benjet C, Georgiades K, Swendsen J (2010) Lifetime prevalence of mental disorders in US adolescents: results from the National Comorbidity Survey Replication-Adolescent Supplement (NCS-A). J Am Acad Child Adolesc Psychiatry 49(10):980989. https://doi.org/10.1016/j.jaac.2010.05.017

12. Jacobi F, Hofler M, Strehle J, Mack S, Gerschler A, Scholl L, Busch MA, Hapke U, Maske U, Seiffert I, Gaebel W, Maier W, Wagner M, Zielasek J, Wittchen HU (2015) Twelve-months prevalence of mental disorders in the German Health Interview and Examination Survey for Adults-Mental Health Module (DEGS1MH): a methodological addendum and correction. Int J Methods Psychiatr Res 24(4):305-313. https://doi.org/10.1002/mpr.1479

13. Merikangas KR, Calkins ME, Burstein M, He JP, Chiavacci R, Lateef T, Ruparel K, Gur RC, Lehner T, Hakonarson H, Gur RE (2015) Comorbidity of physical and mental disorders in the neurodevelopmental genomics cohort study. Pediatrics 135(4):e927938. https://doi.org/10.1542/peds.2014-1444

14. Bekhuis E, Boschloo L, Rosmalen JG, Schoevers RA (2015) Differential associations of specific depressive and anxiety disorders with somatic symptoms. J Psychosom Res 78(2):116-122. https ://doi.org/10.1016/j.jpsychores.2014.11.007

15. Scott KM, Lim C, Al-Hamzawi A, Alonso J, Bruffaerts R, Caldasde-Almeida JM, Florescu S, de Girolamo G, Hu C, de Jonge P, Kawakami N, Medina-Mora ME, Moskalewicz J, Navarro-Mateu F, O’Neill S, Piazza M, Posada-Villa J, Torres Y, Kessler RC (2016) Association of mental disorders with subsequent chronic physical conditions: World mental health surveys from 17 countries. JAMA Psychiatry 73(2):150-158. https://doi.org/10.1001/ jamapsychiatry.2015.2688

16. Brady AM, Deighton J, Stansfeld S (2017) Psychiatric outcomes associated with chronic illness in adolescence: a systematic review. J Adolesc 59:112-123. https://doi.org/10.1016/j.adole scence.2017.05.014

17. Agnafors S, Norman Kjellstrom A, Torgerson J, Rusner M (2019) Somatic comorbidity in children and adolescents with psychiatric disorders. Eur Child Adolesc Psychiatry. https://doi.org/10.1007/ s00787-019-01313-9

18. Lien L, Green K, Thoresen M, Bjertness E (2011) Pain complaints as risk factor for mental distress: a three-year follow-up study. Eur Child Adolesc Psychiatry 20(10):509-516. https://doi. org/10.1007/s00787-011-0211-3

19. Eckhoff C, Straume B, Kvernmo S (2017) Multisite musculoskeletal pain in adolescence and later mental health disorders: a population-based registry study of Norwegian youth: the NAAHS cohort study. BMJ Open 7(2):e012035. https://doi.org/10.1136/ bmjopen-2016-012035

20. Hoftun GB, Romundstad PR, Rygg M (2012) Factors associated with adolescent chronic non-specific pain, chronic multisite pain, and chronic pain with high disability: the Young-HUNT Study 2008. J Pain 13(9):874-883. https://doi.org/10.1016/j.jpain .2012.06.001

21. Mangerud WL, Bjerkeset O, Lydersen S, Indredavik MS (2013) Chronic pain and pain-related disability across psychiatric disorders in a clinical adolescent sample. BMC Psychiatry 13:272. https://doi.org/10.1186/1471-244x-13-272

22. Hoftun GB, Romundstad PR, Zwart JA, Rygg M (2011) Chronic idiopathic pain in adolescence-high prevalence and disability: the young HUNT Study 2008. Pain 152(10):2259-2266. https:// doi.org/10.1016/j.pain.2011.05.007

23. Bair MJ, Robinson RL, Katon W, Kroenke K (2003) Depression and pain comorbidity: a literature review. Arch Intern Med 163(20):2433-2445. https://doi.org/10.1001/archinte.163.20.2433 
24. Mangerud WL, Bjerkeset O, Holmen TL, Lydersen S, Indredavik MS (2014) Smoking, alcohol consumption, and drug use among adolescents with psychiatric disorders compared with a population based sample. J Adolesc 37(7):1189-1199. https://doi. org/10.1016/j.adolescence.2014.08.007

25. Strandheim A, Bratberg GH, Holmen TL, Coombes L, Bentzen $\mathrm{N}$ (2011) The influence of behavioural and health problems on alcohol and drug use in late adolescence-a follow up study of 2 399 young Norwegians. Child Adolesc Psychiatry Ment Health 5(1):17. https://doi.org/10.1186/1753-2000-5-17

26. Johannessen EL, Andersson HW, Bjorngaard JH, Pape K (2017) Anxiety and depression symptoms and alcohol use among adolescents - a cross sectional study of Norwegian secondary school students. Bmc Public Health. https://doi.org/10.1186/s1288 9-017-4389-2

27. Heradstveit O, Skogen JC, Hetland J, Stewart R, Hysing M (2019) Psychiatric diagnoses differ considerably in their associations with alcohol/drug-related problems among adolescents. A Norwegian population-based survey linked with national patient registry data. Front Psychol 10:1003. https://doi.org/10.3389/fpsyg.2019.01003

28. Copeland WE, Adair CE, Smetanin P, Stiff D, Briante C, Colman I, Fergusson D, Horwood J, Poulton R, Costello EJ, Angold A (2013) Diagnostic transitions from childhood to adolescence to early adulthood. J Child Psychol Psychiatry 54(7):791-799. https ://doi.org/10.1111/jcpp.12062

29. Castagnini A, Foldager L, Caffo E, Thomsen PHJEP (2016) Earlyadult outcome of child and adolescent mental disorders as evidenced by a national-based case register survey. Eur Psychiatry 38:45-50

30. World Health Organization. International Classification of Diseases (cited 2019 December 04). https://www.who.int/classifica tions/icd/en/

31. Kaufman J, Birmaher B, Brent D, Rao U, Flynn C, Moreci P, Williamson D, Ryan N (1997) Schedule for affective disorders and schizophrenia for school-age children-present and lifetime version (K-SADS-PL): initial reliability and validity data. J Am Acad Child Adolesc Psychiatry 36(7):980-988. https://doi. org/10.1097/00004583-199707000-00021

32. Goodman R, Ford T, Richards H, Gatward R, Meltzer H (2000) The development and well-being assessment: description and initial validation of an integrated assessment of child and adolescent psychopathology. J Child Psychol Psychiatry 41(5):645-655

33. Diagnostic and Statistical Manual of Mental Disorders, 4th edn. Text Revision ed. 2000. American Psychiatric Association, Washington DC

34. de Vet HC, Mokkink LB, Terwee CB, Hoekstra OS, Knol DL (2013) Clinicians are right not to like Cohen's к. BMJ 346:f2125

35. Mikkelsson M, El-Metwally A, Kautiainen H, Auvinen A, Macfarlane GJ, Salminen JJ (2008) Onset, prognosis and risk factors for widespread pain in schoolchildren: a prospective 4-year follow-up study. Pain 138(3):681-687

36. Fagerland MW, Lydersen S, Laake P (2017) Statistical analysis of contingency tables. CRC Press/Taylor \& Francis Group, Boca Raton

37. Copeland W, Shanahan L, Costello EJ, Angold A (2011) Cumulative prevalence of psychiatric disorders by young adulthood: a prospective cohort analysis from the Great Smoky Mountains Study. J Am Acad Child Adolesc Psychiatry 50(3):252-261. https ://doi.org/10.1016/j.jaac.2010.12.014

38. Ranoyen I, Lydersen S, Larose TL, Weidle B, Skokauskas N, Thomsen PH, Wallander J, Indredavik MS (2018) Developmental course of anxiety and depression from adolescence to young adulthood in a prospective Norwegian clinical cohort. Eur Child
Adolesc Psychiatry 27(11):1413-1423. https://doi.org/10.1007/ s00787-018-1139-7

39. Kim-Cohen J, Caspi A, Moffitt TE, Harrington H, Milne BJ, Poulton RJ (2003) Prior juvenile diagnoses in adults with mental disorder: developmental follow-back of a prospective-longitudinal cohort. Arch Gen Psychiatry 60(7):709-717

40. Kessler RC, Avenevoli S, Costello EJ, Georgiades K, Green JG, Gruber MJ, He J-p, Koretz D, McLaughlin KA, Petukhova M (2012) Prevalence, persistence, and sociodemographic correlates of DSM-IV disorders in the National Comorbidity Survey replication adolescent supplement. Arch Gen Psychiatry 69(4):372-380

41. Ginsburg GS, Becker-Haimes EM, Keeton C, Kendall PC, Iyengar S, Sakolsky D, Albano AM, Peris T, Compton SN, Piacentini J (2018) Results from the child/adolescent anxiety multimodal extended long-term study (CAMELS): primary anxiety outcomes. J Am Acad Child Adolesc Psychiatry 57(7):471-480

42. Ottosen C, Larsen JT, Faraone SV, Chen Q, Hartman C, Larsson H, Petersen L, Dalsgaard S (2019) Sex differences in comorbidity patterns of attention-deficit/hyperactivity disorder. J Am Acad Child Adolesc Psychiatry 58(4):412-422 (e413)

43. Sareen J, Cox BJ, Clara I, Asmundson GJG (2005) The relationship between anxiety disorders and physical disorders in the US National Comorbidity Survey. Depress Anxiety 21(4):193-202. https://doi.org/10.1002/da.20072

44. Jones LC, Mrug S, Elliott MN, Toomey SL, Tortolero S, Schuster MA (2017) Chronic physical health conditions and emotional problems from early adolescence through midadolescence. Acad Pediatr 17(6):649-655. https://doi.org/10.1016/j.acap.2017.02.002

45. King S, Chambers CT, Huguet A, MacNevin RC, McGrath PJ, Parker L, MacDonald AJ (2011) The epidemiology of chronic pain in children and adolescents revisited: a systematic review. Pain 152(12):2729-2738. https://doi.org/10.1016/j.pain.2011.07.016

46. Skrove M, Romundstad P, Indredavik MS (2015) Chronic multisite pain in adolescent girls and boys with emotional and behavioral problems: the Young-HUNT study. Eur Child Adolesc Psychiatry 24(5):503-515. https://doi.org/10.1007/s00787-014-0601-4

47. Gobina I, Villberg J, Valimaa R, Tynjala J, Whitehead R, Cosma A, Brooks F, Cavallo F, Ng K, de Matos MG, Villerusa A (2019) Prevalence of self-reported chronic pain among adolescents: evidence from 42 countries and regions. Eur J Pain (Lond, Engl) 23(2):316-326. https://doi.org/10.1002/ejp.1306

48. Kraus L, Nociar A (2016) ESPAD report 2015: results from the European school survey project on alcohol and other drugs. European Monitoring Centre for Drugs and Drug Addiction, Lisbon

49. Strandheim A, Holmen TL, Coombes L, Bentzen N (2009) Alcohol intoxication and mental health among adolescents-a population review of 8983 young people, 13-19 years in North-Trondelag, Norway: the Young-HUNT Study. Child Adolesc Psychiatry Ment Health 3(1):18. https://doi.org/10.1186/1753-2000-3-18

50. Degenhardt L, Stockings E, Patton G, Hall WD, Lynskey M (2016) The increasing global health priority of substance use in young people. Lancet Psychiatry 3(3):251-264

51. Kedzior KK, Laeber LT (2014) A positive association between anxiety disorders and cannabis use or cannabis use disorders in the general population - a meta-analysis of 31 studies. BMC psychiatry 14:136. https://doi.org/10.1186/1471-244x-14-136

52. Nelemans SA, Hale WW 3rd, Raaijmakers QA, Branje SJ, van Lier PA, Meeus WH (2016) Longitudinal associations between social anxiety symptoms and cannabis use throughout adolescence: the role of peer involvement. Eur Child Adolesc Psychiatry 25(5):483-492. https://doi.org/10.1007/s00787-015-0747-8

53. Turner S, Mota N, Bolton J, Sareen J (2018) Self-medication with alcohol or drugs for mood and anxiety disorders: a 
narrative review of the epidemiological literature. Depress Anxiety 35(9):851-860. https://doi.org/10.1002/da.22771

54. Picoito J, Santos C, Loureiro I, Aguiar P, Nunes C (2019) Genderspecific substance use patterns and associations with individual, family, peer, and school factors in 15-year-old Portuguese adolescents: a latent class regression analysis. Child Adolesc Psychiatry Ment Health 13(1):21

55. Molina BSG, Howard AL, Swanson JM, Stehli A, Mitchell JT, Kennedy TM, Epstein JN, Arnold LE, Hechtman L, Vitiello B,
Hoza B (2018) Substance use through adolescence into early adulthood after childhood-diagnosed ADHD: findings from the MTA longitudinal study. J Child Psychol Psychiatry 59(6):692702. https://doi.org/10.1111/jcpp. 12855

56. Andrews G, Slade TJP (2002) The classification of anxiety disorders in ICD-10 and DSM-IV: a concordance analysis. Psychopathology 35(2-3):100-106 